\title{
И.Н. Круглова
}

\section{ТВОРЕНИЕ ЕХ NIHILO В ПРОСТРАНСТВЕ ФИЛОСОФСКОГО ДИСКУРСА}

\begin{abstract}
В иентре внимания статьи - идея творения ех nihilo в контекстах учения о Софии Вл. Соловьева и С.Н. Булгакова, понятия «отрииания» С.Л. Франка и конструкта differance Ж. Деррида. Показано, как способы решения вопроса о соотношении Твориа и творения форматируют модели русской метафизики, с одной стороны; с другой как постметафизический дискурс философии - понятие «денегаџии» Ж. Деррида проясняет металогический характер «ничто»в определении спеиифики «тварного ничтожества».

Ключевые слова: творение ех nihilo; учение о Софии, постметафизика; всеединство; отрииание; differance; Вл. Соловьев; С.Н. Булгаков; С.Л. Франк; Ж. Деррида.
\end{abstract}

Основная цель данной статьи - показать, как идея творения ex nihilo, сформулированная в христианском дискурсе в качестве догматического постулата, способна провоцировать новые форматы философского дискурса в поисках такой рациональности, когда опыт веры сочетается с опытом разума, когда, по словам В.С. Соловьева, «философия получает свое содержание от знания религиозного, или теологии, разумея под этою последнею знание всего в Боге» [1. Т. 1. С. 737]. В этом плане в центре нашего внимания будет находиться идея творения и то, как она представлена в русской религиозной метафизике, прежде всего, у таких мыслителей, как Вл. Соловьев, С.Н. Булгаков и С.Л. Франк. Нам интересно проследить и обратный процесс, который, на наш взгляд, наблюдался в период постметафизического поворота в философии: как повлияла критика классической метафизики на способы осмысления идеи творения, в конечном итоге тоже способствующей трансформации предметного поля современной философии. И здесь точкой притяжения будет деконструктивистский проект Ж. Деррида, а именно, парафраз идеи творения в конструкте differance, ставшем визитной карточкой французского мыслителя.

«Творение» есть то понятие, оригинальность которого осмысляется с появлением христианского мировоззрения: это понятие определяет собой отношение Бога к миру. Если Бог определяется в соответствии со строгой процедурой апофатизма, как Божественное Ничто, то таким же образом определяется и тварное начало, по словам Вл. Лосского, при помощи «апофатизма вспять». Необходимо помыслить такую природу тварного ничто, которое, имея начало, никакой природой или сущностью не обладает, поскольку равной с Богом сущности быть не может. С другой стороны, все упирается в новые отношения, которые объявляет благая весть между человеком и Богом: человек спасен, а значит, непроходимая грань между двумя природами божественной и человеческой - преодолена. Но как помыслить «преодоле- 
ние»: как смешение, рядоположенность, импликацию? Куда «поместить» «мирское»: «внутри» или «рядом» с «божественным», как провести эту тонкую грань, соединяя, но при этом не смешивая, разделяя, но при этом питая одним источником, одним основанием?

Особенность христианского «творения» как понятия в том, что оно, обозначая творение мира, тем не менее само не принадлежит этому миру. Творение - это та черта, которая разделяет Творца и творение: с одной стороны, принадлежит Творцу, но не со-вечна Ему (так как является не природой Его, но актом воли); с другой стороны, эта «точка» означает начало творения, но как причина творения не принадлежит самому творению, не со-положна ему как своему результату. Другими словами, как Творец Бог присутствует в своем творении, но Он - не есть это творение, не есть его сущность; мир есть только результат его действий. Именно в этом вопросе разошлись платонизм и учение о Божественных энергиях Гр. Паламы: понятие «энергии» как раз определяет не сущностное соединение Творца и твари, а энергийное, т.е. по причастию к благодати.

Уже в неоплатонизме - философском направлении, предшествующем христианскому дискурсу, - акцентируются особые взаимоотношения между Единым и миром. Чтобы подчеркнуть не причинно-следственный характер этих взаимоотношений, - отношений, не мотивированных никакой необходимостью, - Плотин применяет слово «эманация»: Единое истекает, эманирует, словно переполненная чаша; а также слово «свечение» (см.: [2. С. 403]): Единое, будучи светом, светит вокруг себя, в силу собственной природы свечения производя мир. Неоплатоники ближе всех подобрались к христианской идее творения, но и они были весьма далеки от того, чтобы обозначить ее как творение ex nihilo.

«Творение из ничего» - понятие-парадокс, поскольку подразумевает под «ничто» не некую первоматерию и даже не пустоту (это уже что-то), а абсолютное ничто - что является по сути немыслимым в пределах мышления представлением: ведь, обозначив «ничто» как «ничто», мы уже дали ему жизнь, смысл и понимание. «Тварное ничтожество, - рассуждает Вл. Лосский, - столь же таинственно и немыслимо, как и божественное "не-есть" отрицательного богословия. Сама идея абсолютного “ничто” - противоречива, абсурдна: сказать, что оно существует, - значило бы противоречить самому себе; сказать, что оно не существует, - было бы плеоназмом, разве что мы хотели бы неудачным образом выразить мысль, что ничего не существует вне Бога, что даже не существует и само “вне"» [3. С. 154].

Комментируя Иоанна Дамаскина, Вл. Лосский находит более удачную формулировку: творение из ничего означает, что Бог дает существование абсолютно новому сюжету, не обоснованному никакой Божественной природой, ни какой-либо материей, ни еще чем-либо, ведь «никакая необходимость не понуждала Бога творить» [3. С. 155]. Бог вне мира, но в то же время внутри мира. Это отношение со-причастности можно выразить такой парадоксальной формулировкой: мир существует всегда и во все времена как вечное отсутствие вечного Его присутствия. Мир наш не является божественным по природе, но связан с Богом «кровной» связью («Бог-Отец»). Обо- 
значая ее как любовь («Бог есть любовь»), благая весть акцентирует выпадающее из нашего поля зрения обоснование этой связи.

И в этом плане творение как акт воли (не субстанциальный и не сущностный для тварного мира) разнится с рождением Логоса как сущностной характеристикой второго Лица Троицы. Рождение - особое отношение внутрибожественной жизни - безначальное и предвечное, не-количественное (здесь нет первого и второго, третьего); такова вечная природа Отца: рождать Сына и исходить Духом Святым. Творение же - переход от небытия к бытию; нечто, имеющее начало, причем начало, погруженное в ничто - ex nihilo. Как апофазис в понимании сущности Бога приходит к тому, что Он не-есть (не есть что-либо, присущее бытию, ибо Он сверх бытия), так и тварное существование берет свой исток в некоем не-есть. Но какова природа этих двух «неесть» и можно ли их соотнести?

Собственно, здесь, в этой проблемной точке сопряжения божественного и человеческого, в этом труднопостижимом месте состыковки двух природ (и в месте невозможной возможности для человеческой способности об этом говорить), возникает софинианство как учение о посредничестве между Творцом и творением.

Учение о Софии в русской религиозной метафизике репрезентировало идею творения и, по сути, предлагало один из оригинальных путей решения этой проблемы как проблемы философского дискурса. Софиология в данной версии строится по модели пан-эн-теизма. В русской философии первый, кто применил эту логическую модель построения философской системы, был Вл.С. Соловьев. Пан-эн-теизм заключается в соединении, с одной стороны, традиции пантеизма, сформулированной Н. Кузанским, Дж. Бруно, развитой Спинозой, Гегелем, Шеллингом и заключающейся в понимании Бога как совпадения противоположностей. С другой стороны, к изначальному пантеистическому тезису присоединяется догмат о Троице, требующий жесткого разграничения Творца и творения. Также и у Соловьева мы находим похожую схему: с одной стороны, сущее есть тождество противоположностей: Единого и материи, с другой стороны, сущее - единство трех ипостасей в одной (божественной) природе.

Разграничить Творца и творение русский философ попытался с помощью неоплатонического учения о Едином. Неоплатоники, чтобы подчеркнуть абсолютную, ни к чему не сводимую, природу Единого, мыслили его двойственно: Единое, не причастное многому (устроенное по принципу внутрибожественной тройственности), и Единое, причастное многому (т.е. изливающееся вовне). Второе Единое Соловьев и определит как первоматерию, «душу мира», а затем как Софию - Премудрость Божию, состоящую посредником между Творцом и творением.

Соединение двух разных традиций дало Соловьеву возможность сформулировать концепцию так называемого конкретного идеализма (или мистического реализма), когда абсолютное мыслится как все-единое, которое есть единство самого себя и своего другого - не отвлеченная идея, а реальное существо, в котором противоположности не уничтожаются, синтезируясь, а сосуществуют (по образу догмата о св. Троице, в котором утверждается нераздельность природы, но и неслиянность в Лицах). Именно здесь заложено 
то, что станет впоследствии «базовым концептом “положительного всеединства”» [4. С. 209] для всей русской метафизической традиции. Развивая идею всеединства и решая заложенные в ней противоречия, русская философия достигнет своего расцвета и выразит основные проблемы и ведущие программы современной философии.

Итак, согласно неоплатонической схеме, Соловьев утверждает «первое абсолютное», не причастное миру, и «второе абсолютное», обращенное $\kappa$ миру (или абсолютное-само-в-себе и абсолютное-для-иного). В этом плане Соловьев близок к святоотеческому пониманию Софии, например, представленному у Афанасия Великого как Софии Божественной и Софии тварной. Однако в этом делении у св. Афанасия нет ничего пантеистического: творение имеет отношение к первой Софии только благодаря двойственной природе Христа. У Соловьева получается так: идеальная сущность творения уже содержится в Софии как некая идеальная основа Бога, Его иное. Начиная с «Философских начал цельного знания» на протяжении всего творчества русского мыслителя так и остается непроясненным различие Софии и Христа, Софии и Духа Святого, Софии и тварного мира.

В этом плане А.Ф. Лосев считает, что Соловьева могло бы спасти от обвинений в пантеизме более продуманное отношение к понятию «отрицание»: если бы внебожественное инобытие (мир, человек, история) не истолковывалось основателем русской философии как самоотрицание Абсолютом самого себя, это «могло бы спасти внебожественное инобытие от субстанциальной божественности и тем впервые уничтожить пантеизм в корне» [5. С. 125]. Но вот что интересно: тот же Лосев добавляет, что Соловьева ни в коем случае нельзя считать пантеистом, «так как он был ревностным защитником христианства, которое считается строжайшим монотеизмом» [5. С. 122123]. Так в чем же дело? По Лосеву, Соловьев в своей философии далеко не всегда был аккуратен в понятийной проработке своего учения, и данная неадекватность в выражении привела в итоге к отсутствию «четкого учения о различии творца и твари» [5. С. 119]. В более поздней работе, «Чтениях о Богочеловечестве», Соловьев попытался скорректировать неувязки своего учения о Софии, но и здесь смешение пантеистических и теистических мотивов дает о себе знать.

В Соловьеве всегда борются два начала: христианский дух с его стремлением к прояснению богочеловеческой природы Бога и творения (мысль, бесконечно варьирующая у русского философа: Бог в силу своей полноты и совершенства нуждается в человеке и его свободе) и классический образ мышиления, характерный для академической философии второй половины XIX века. Дело в том, что классическое метафизическое мышление не позволяет превратить природу «мирского» начала «в абсолютно непознаваемый нуль, в абсолютное ничто» [5. С. 107], в «отрицание», не сливающееся и не растворяющееся в божественном единстве. Однако существо вопроса о соотношении Творца и творения в конечном итоге приводит к осмыслению природы «ничто», которую необходимо обозначить как радикально иную (только в этом случае мы можем надеяться на подлинное разграничение «божественного» и «мирского»). Укоренение человеческой природы не в сущностной (платоновской) диалектике, а в негативной - таково одно из основных отли- 
чий современной философии от классической. Русская философия оказалась на самом рубеже проблемы, и этот рубеж особенно отчетливо просматривается в учение о Софии.

В основе софиологии С. Булгакова лежит все та же схема пан-эн-теизма. Однако, в отличие от Соловьева и всей немецкой традиции, имевших тенденцию к вытеснению христианской идеи творения как принципиального различия между Творцом и творением и ее замене идеей божественной трансцендентности как глубины бытия, Булгаков подчеркивает в этом вопросе первенствующее значение апофатического понимания: между Да творческого акта и Нет тварности не существует никакого диалектического перехода; мир не есть некое «ничто» Бога, Его собственная бездна, из которой мир развернулся в силу естественного развития. Божественное «да будет» всегда остается чудом и создает мир «из ничего», т.е. первоначальным актом будет обличение этого абсолютного «ничто» в первоматерию («меон» с греч.).

Разбирая учение св. Афанасия Великого о Премудрости Божьей, Булгаков ставит вопрос: как можно мыслить отношение Бога к миру без умаления абсолютности Божества и без умаления самобытности мира? «Отсюда естественно проистекает стремление искать посредства... поставить между Богом и миром некую сверхтварь, заслоняющую собою мир от Бога и сгорания в огне попаляющем» [6. С. 265]. Но это посредство, - рассуждает философ, - не есть некое срединное положение; кроме того, оно «не необходимо для Бога, но возможность его дана в Нем» [6. С. 268]; кроме того, оно не может быть непосредственным действием Бога «как бы за пределами Своего собственного бытия, как создание чего-то нового, доселе не бывшего и в Боге не сущего» [6. С. 269], ведь тогда грань между Богом и миром сотрется, ибо получается Бог и Сам не знал мира до его творения, а значит, вос-полнился им. Поэтому решение, считает Булгаков, может быть только одно: София - это предвечный мир, предвечное основание мира в Боге, «тварным образом которого, проекцией во времени, является мир сотворенный» [6. С. 269]. И поскольку Бог все творит предвечным Логосом, Сыном Божьим, то необходимо различать предвечную Премудрость и ее тварное воплощение (как сотворенное Словом).

«Софиология, - поясняет современный исследователь софиологии и имяславия Е. Гурко, - есть учение о божественной мудрости как Святой Софии, снизошедшей в тварный мир, о мистическом единении Бога и творения. Софиология традиционно является одним из важнейших доктринальных течений православия, поворотный пункт которого связывается со святоотеческой интерпретацией с ее разделением тварных и нетварных аспектов мудрости» [7. С. 159]. Именно это и ставится в заслугу Булгакову - обоснование двух типов Софии - божественной и тварной. Тогда почему же в 1935 г. «в редчайшем, если не уникальном, порыве согласия Московский патриархат и конкурирующий с ним эмигрантский Синод Русской православной церкви осудили софиологию Булгакова как еретическую» (цит. по: [7. С. 161])?

На наш взгляд, все дело заключается в осмыслении «ничто», которое, как мы уже показывали, по Булгакову, нельзя представить как существующее «до сотворения», следовательно, по его мнению, «Бог сотворил мир из Самого себя» (цит. по: [7. С. 165]). Миротворение как мысль Бога, Божественная Со- 
фия, получается, со-вечна Богу и также, получается, со-вечен воплощенный через Нее тварный мир. Другими словами, Булгаков практически отождествил нетварную Софию и тварный мир, рассматривая их разницу не как сущзностную, но как разницу модусов существования. «Материя - Матерь - меон, - пишет Булгаков в «Свете Невечернем», - есть необходимая основа бытия» [8. С. 188], потенциальная сущность бытия, содержащая в себе всю полноту творения, всю тайну мира. И в «Невесте Агнца» добавляет, что она также составляет «вечную, несотворенную, божественную основу мира в Боге» (цит. по: [7. С. 165]).

Итак, согласно русскому философу, София Божественная - божественный «проект» мира - вечная, несотворенная, божественная основа мира; София тварная, по сущности не отличаясь от первой Софии, также божественна и есть «душа тварного мира, его сверхтварная мудрость, как бы божественный инстинкт тварного бытия, ангел-хранитель твари, сама субстанция тварности, погруженная в ничто» (цит. по: [7. С. 166]).

Очевиден тот факт, что функции Логоса как второго Лица Троицы переданы Булгаковым меону-материи, и, соответственно, Софии принадлежит основная роль при переходе от божественного мира к сотворенному. В этом плане С. Булгаков так же, как, к примеру, и П. Флоренский, не избежал абсолютизации Софии как четвертого начала в контексте христианского тезиса о триипостасности божественной природы. Другими словами, чтобы преодолеть «сумерки пантеизма» [6. С. 265], мыслитель приблизил «тварность» к понятию «ипостасности» и не смог в конце концов четко их дифференцировать.

Е. Гурко, комментируя позицию С.Н. Булгакова в отношении софиологии, подчеркивает его стремление через идею творения придать ей максимально христианский характер (см.: [7. С. 164]). Несмотря на эти усилия, софианический характер универсума Булгакова, в котором божественная мудрость разлита везде и повсюду, растворяет идею творения в божественной сущности: превознесение тварного ничтожества до возведения в ранг божественной природы оборачивается потерей - потерей уверенности в посреднике между Богом и человеком: выходит, человек спасен до Христа, в Софии, и что тогда остается на долю человека? Служить поставщиком собственной мудрости?

Камень преткновения русской софиологии - понятие «тварного ничтожества» и его соотнесение с нетварной природой Софии. Нам представляется, что выход из этого круга взаимоопределения подсказывают рассуждения С.Л. Франка о природе «Непостижимого» в одноименной работе мыслителя, написанной им в 1938 г.

С.Л. Франк, создавший еще один вариант религиозно-метафизического «мистического реализма» (по авторскому определению - «идеал-реализм»), тем не менее не является сторонником учения о Софии. Несмотря на то, что русский мыслитель движется в контексте базового концепта «положительного всеединства», он не использует непосредственно модель пан-эн-теизма. Однако, решая задачи онтологического обоснования интуитивизма, он также движется в пространстве двух родов Абсолютного: первого - трансцендентного, трансрационального Непостижимого, которое способно воплощаться в 
бытии, и второго - неповторимой конкретной личности, также непостижимой и избыточной в своей полноте. Схема идеал-реализма также держится на представлении о двухслойности бытия, «в котором единство задается не субстанциально, а через систему связей и отношений, существующих во времени реальных ситуаций с их каузальными зависимостями и представленных во вневременных формах, телеологически продуцирующих смыслы и цели деятельности» [9. С. 1112].

Другими словами, для Франка модель всеединства имеет, прежде всего, методологическое значение как модель единого, которое существует не за счет или в ущерб своим элементам, а за счет того, что «единство сохраняет и усиливает свои элементы, осуществляясь в них как полнота бытия» [10. Т. 2. С. 552]. Для С.Л. Франка всеединство - это место, где встречаются единство элементов и их не утраченная в процессе объединения множественность и специфичность. Особенность подхода Франка к всеединству - в антиномизме противоположностей: Творец и творение, Бог и человек, сущее и материя, единство и множественность нигде, никогда, ни в какой точке не отождествляются непосредственно. Можно говорить только о месте их антиномического совпадения. И это место представляет собой нечто особенное, «как бы стоящее на пороге» нашего разумения [11. С. 394], благодаря которому мы имеем единственную возможность мыслить абсолютную реальность, трансрациональную и таинственную по существу. Это и есть всеединство - всеобъемлющее бытие, которое одновременно и дано нам, и уже не дано; эта реальность рационально постижима, но только, если мы задействуем особую стратегию «умудренного неведения», в которой главную роль играет «мощь отрицания».

Франк переосмысливает принцип гегелевского «отрицания отрицания» и формулирует принцип «потенцированного отрицания». По мнению Франка, гегелевское отрицание, завершая трехступенчатый путь развития положительным синтезом, на самом деле обманчиво, потому что теряет, отклоняет свою абсолютную силу отрицания: нельзя поспешно переходить от абсолютного отрицания к абсолютному тождеству. Необходимо, чтобы Отрицание всегда сохраняло свою способность отрицать, преобразуясь в более основополагающий онтологический принцип, обозначающий некое первичное глубинное единство с Тождеством как принцип различения и различенности. Отрицание должно не только отрицать, но и упрочивать связь различного. Отрицание не должно изгоняться из состава реальности; необходимо сохранить положительный онтологический смысл и ценность отрицания: «Истинный смысл отрицания заключается в различении, различение же означает усмотрение различия, дифференцированности бытия как его положительной онтологической структуры» [11. С. 418]. «Отрицательное отношение» принадлежит к самому составу бытия и в этом смысле не может быть само отрицаемо. Улавливая истинный смысл отрицания, считает С.Л. Франк, мы тем самым возвышаемся над ним, утверждая реальность в форме негативно$c m u$, а это и есть способность бытия становиться тем, что оно еще не есть.

Если и говорить о синтезе, то это будет воплощение «непостижимого» и его положительное определение будет состоять, по словам русского философа, в «свободном витании над противоречием и противоположностью», в 
результате чего открываются горизонты мира, куда погружены предметности, это - место, почва укорененности мира. И в этой укорененности Ничто соседствует с Бытием, никогда с ним до конца не ассимилируясь. Такая онтологическая установка определяется Франком как антиномистический монодуализм.

Чтобы определить суть антиномистического монодуализма как соотношения Творца и творения, Франк использует слово «конвергенция». Конвергенция и есть то самое искомое взаимопроникновение Тождества и Различного без упразднения их обоих. Рассуждая о первоосновании бытия как о нечто большем, чем само бытие, С.Л. Франк подчеркивает, что два слоя бытия, два мира, несмотря на всю несогласованность и противоречивость, конвергируют, т.е. сходятся между собой, не растворяясь в неразличимое нечто, но сближаясь в бесконечной глубине и дали. Главное, о чем не следует забывать, по мнению Франка, - нельзя преобразовать в свою противоположность и тем самым вычеркнуть из абсолютной реальности начало различия, обозначающее не ограниченность нашего познания, но «субстанциональное основание самого бытия» [12. С. 271].

Безусловно, С.Л. Франк движется в сторону того, что впоследствии будет характерно для постметафизики в понимании ничто как принципа разведения бытия и не-бытия, разрывающего самотождественность любого присутствия: как Не-начального Начала, как неустранимой деструкции сущего и «изначального опоздания» и т. п. И в этом плане своим определением «потенцированного отрицания» он предвосхищает, к примеру, понятие «различающего различия» Жака Деррида, которое, на наш взгляд, открывает новые перспективы для осмысления идеи творения ex nihilo.

Деррида, в качестве одного из самых категоричных критиков метафизи$\kappa u$, находится в поиске uных ресурсов для решения классических философских вопросов. В частности, он затрагивает и проблему определения тварного «ничто», отзвук которой мы находим в таких его понятиях-конструктах: след, differance, nра-письменность и др., ставших визитной карточкой мыслителя. Перечисленные понятия в рамках деконструктивистского проекта Деррида призваны, прежде всего, выразить парадоксальность нашего пребывания в мире, иллюзорность человеческих претензий на прочность оснований собственного бытия. Итак, поставим вопрос таким образом: может ли дискурс постметафизики продвинуть нас в осмыслении понятия «творения», минуя вскрытое софиологией смешение тварного и нетварного аспектов бытия при попытке сохранить и абсолютность Творца, и самобытность творения?

Известно, что под differance Деррида имеет в виду специфику человеческого мира. Но этот мир очень странный - он старше самого Бытия, потому что основанием его является Ничто не как соотносимое с «Нечто», но как несущиноть всего, что затем способно обретать сущность. В таком качестве Ничто изначальнее Бытия, но как бы все время запаздывает по отношению к нему, подавляясь его силой явления и вытесняясь на второй план. Поэтому «ничто» практически невозможно «ухватить» в логических конструкциях и сказать нечто о нем, ведь все, что осмыслено и сказано, уже получило некую бытийственность. Конечно, эти рассуждения весьма напоминают ту работу мысли, которая происходит при апофатическом определении Бога, на- 
пример, в негативной теологии, и французский философ пытается соотнести свою методологию и методологию последней.

В своих ранних работах Деррида пишет, что «differance... включает в себя и превышает, причем необратимо, онто-теологию или философию» [13. С. 129]. Есть существенная разница между не-есть негативной теологии и неecmb differance. Ведь Деррида постоянно подчеркивает не трансцендентный, а имманентный характер последнего. Но этот имманентизм опять-таки имеет не традиционную природу сопричастности бытию; он все время оборачивается нулем, пропастью, бездной. Differance, являясь без-основной основой мира, в то же время ему не принадлежит: это Не-начало одновременно находится внутри мира (как то, без чего мир не сможет состояться, точнее, длиться ) и за гранью нашего мира (как то, куда мир постоянно проваливается, где он распыляется, по словам Деррида, на множество субститутов). Пограничный характер differance дает возможность появиться миру: появиться и тут же исчезнуть, оставив след, напоминание; через эти следы и длится бытие.

Считается, что концептом differance Деррида сумел выразить ускользающую природу конечного человеческого мира - мира без почвы, мира абсолютного исчезновения, стирающего следы Бытия и человека в нем мира не-существующего, но тем не менее единственного из всех возможных миров, в котором человек как таковой способен себя обнаружить (см.: [14. С. 30]).

Итак, человек не присутствует в бытии ни пространственно, ни временно; он находится, скорее, на грани бытия и не-бытия - в мире differance. Это может вести к пониманию differance как божественного начала. На собрании Французского философского общества, где Деррида сделал свой доклад в 1968 г., такой вопрос и был ему задан: «Если она [differance] есть источник всего и непознаваема, то тогда она - Бог негативной теологии»? Ответ Деррида был: «И да, и нет» (цит. по: [7. С. 334-335]). Что хотел сказать Деррида? Приведем комментарий по этому поводу Е. Гурко: «Уже для ранней деконструкции было достаточно очевидно, что, создавая свой мир - несуществующий мир не-бытия (differance), человек подражает Богу, действует как Бог. Деррида доводит это представление до его логического конца, указывая, что differance подражает божественности, повторяет исходный жест творения в его аутентичной форме отрицания Бытия. Differance, таким образом, не Бог, но действует, ведет себя, как Бог» [7. С. 335].

Итак, взаимоотношение differance $и$ Бога было озвучено уже в ранних работах Деррида, однако только в поздний период эта проблема получает проработку, в связи с чем исследователи говорят о так называемом религиозном повороте французского философа. В поздний период своего творчества Деррида произвел деление универсума уже на три сферы: мир божественный (divinite), мир человеческий (differance) и мир природный (presence).

В своем «путешествии на край света» (в предельную точку языка, мышления и бытия) деконструкция обнаружила ту пустоту, то великое распыление, о котором повествовали великие мистики и богословы. Что определила деконструкция уже на первых этапах своего анализа? Как мы уже указывали, то, что человеческий мир организован как мир differance, как негация - отри- 
цание Бытия. В более поздней работе «Как избежать разговора: денегациии» Деррида добавит в отношении мира differance двойную негацию - денегацию, которая означает, что человек, являя собой ничто Бытия и будучи тем самым старше Бытия, способен наделять его смыслом. Первая негация относится к возможности существования человека как такового, вторая - к его возможности давать всему имена, т.е. наделять вещи смыслом. Другими словами, вторая негация относится к тому, что человек является существом говорящим, язык же построен на принципе различия.

Встает законный вопрос: откуда у человека такая способность к негативности - к творческой негативности, созидающей человеческий мир, - к негативности, превосходящей мир Бытия и становящейся «ресурсом, источником всего того, что изгоняет, уничтожает, распыляет и превосходит настоящее как присутствие» (цит. по: [7. С. 429])? Пожалуй, только творческое ex nihilo христианского дискурса обладает тем потенциалом, в котором можно найти бесконечную производительность отрицания. И Деррида формулирует доказательство Бытия Божьего, исходя, как и негативная теология, из возможности отрицания: «Бог» будет именовать то, без чего невозможно понять какое бы то ни было отрицание: грамматическое или логическое, болезнь, зло или невроз...» [15. С. 254-255]. Для французского философа негация негативной теологии, что называется, «человеческая, слишком человеческая»; она обращена только к дискурсу о Боге, тогда как деконструкция саму возможность человека к дискурсивности объявляет теологической: имя Бога - это образец, иллюстрация всех имен. Деконструкция максимально радикализирует негативную манеру в отношении всего дискурса: все, что можно поименовать и, соответственно, дать место в пространстве творения, есть производство абсолютной божественности отрицания: «Бог является истиной всего отрицания» [15. C. 254-255].

Именно эта отрицательность маркирует, что мир создан Богом, но мир не есть Бог; автономность Бога сохраняется тем, что Он отрицает мир, но при этом остается причиной бытия - присутствующим отсутствием. Сама возможность именования свидетельствует о Творце как источнике всего и творении ех nihilo как непричиненных плодах, плодах без причины: творение существует в силу отрицания Богом Своей природы. Повторимся, по определению только Бог может иметь бесконечный запас отрицательности, в котором вызревает пространство для человеческого смыслополагания.

Итак, подводя итоги нашим размышлениям, можно сказать: русская метафизическая традиция в лице Вл.С. Соловьева и С.Н. Булгакова, решая проблему определения «тварного ничто» через учение о Софии, постоянно находится в искушении возвести, возвеличить тварность к божественной сущности. Смешанность нетварных и тварных аспектов Софии происходит от того, что достаточно четко не была прояснена природа «ничто» как металогического начала бытия. Именно в этом направлении движется мысль С.Л. Франка: ничто как «потенцированное отрицание», как отрицание, которое не может быть преодолено в своей абсолютности, есть единственный способ утверждения реальности Божественной в ее соотнесении с реальностью человеческого мира. В результате Франк становится весьма близок то- 
му, что впоследствии определится в постклассической философской традиции как метафизика Различия: в частности, к истолкованию Деррида ничто как различающего начала, как не-сущности творения, как денегации - двойного отрицания, как мира differfance, который является образом и подобием бесконечной божественной производительности отрицания, творящей мир и таким образом дающей ему свободу самоопределения. Однако эта свобода не имеет своей сущности; ее сущностью является причастность к Богу как причине своего творения. Подобно тому, как когда-то святые Отцы Церкви, настаивая на пересмотре оснований классической греческой философии и невозможности ее средствами выразить новый опыт веры, а значит, и мышление о вере, дали возможность состояться не только маргинальным мистическим направлениям в философии, но также и поискам новых логических моделей классических философских систем; точно так же и постметафизический способ говорить об истине, бытии и человеке, преодолевая издержки логоцентризма и открывая пространство постметафизического способа говорить о Боге, обогащает арсенал теологической проблематики, в том числе и понимания идеи творения ex nihilo как присутствующего отсутствия Творца.

\section{Лumepamypa}

1. Соловьев В.С. Критика отвлеченных начал // Соловьев В. С. Сочинения в 2 т. М.: Мысль, 1990. T. 1. C. $581-745$.

2. Чаныщев А.Н. Курс лекций по древней и средневековой философии. М.: Высш. шк., $1991.512 \mathrm{c}$.

3. Лосский Вл. Очерк мистического богословия Восточнй Церкви // Лосский Вл. Мистическое богословие. Киев: Путь к истине, 1991. С. 95-261.

4. Круглова И.Н., Круглов В.Л. С.Л. Франк и Ж.Деррида: необходимость невозможного // Феноменолого-онтологический замысел Г.Г.Шпета и гуманитарные проекты XX-XXI веков: Г.Г. Шпет / Comprehensio. Шестые Шпетовские чтения: сборник статей и материалов международной научной конференции (1-7 июня 2015 г.). Томск, 2015. С. 203-214.

5. Лосев А.Ф. Вл. Соловьев. М.: Мысль, 1983. 208 с.

6. Булгаков С.Н. Купина неопалимая. Париж, 1927. 288 с.

7. Гурко Е. Божественная ономатология: Именование Бога в имяславии, символизме и деконструкции. Мн.: Экономопресс, 2006. 448 с.

8. Булгаков С.Н. Свет Невечерний: Созерцания и умозрения. М.: Республика, 1994415 с.

9. Абушенко В.Л. Франк С.Л. // Новейший философский словарь: 2-е изд., перераб. и доп. Мн.: Интерпрессервис; Книжный дом. 2001. С. 1110-1112.

10. Соловьев В.С. Первый шаг к положительной эстетике // Соловьев В.С. Сочинения в 2 т. 2-е изд. Т. 2 / общ. ред. и сост. А.В. Гулыги, А.Ф. Лосева; примеч. С.Л. Кравца и др. М.: Мысль, 1990. C. $548-556$.

11. Франк С.Л. Непостижимое // Франк С.Л. Сочинения. Мн.: Харвест. М.: АСТ, 2000. 800 с.

12. Новикова Л.И., Сиземская И.Н. Русская философия истории: Курс лекций. М.: ИЧП «Издательство Магистр», 1997. 328 с.

13. Деррида Ж. Differanse // Гурко Е. Тексты деконструкции. Томск: Водолей, 1999. С. 124-158.

14. Гурко Е. Тексты деконструкции // Деррида Ж. Differanse. Томск: Водолей, 1999. С. 3-124.

15. Деррида Ж. Как избежать разговора: денегации // Гурко Е. Деконструкция: тексты и интерпретация. Мн.: Экономпресс, 2001.

Inna N. Kruglova. Federal State Budgetary Educational Institution of Higher Education «Krasnoyarsk State Agrarian University» (Krasnoyarsk, Russian Federation)

E-mail: inna_krug@mail.ru

DOI: $10.17223 / 1998863 X / 39 / 13$

CREATION EX NIHILO IN THE SPACE OF PHILOSOPHICAL DISCOURSE 
Key words: creation ex nihilo; the doctrine of Sophia, postmetaphysics; unity; denial; differance; V1. Solovyov, S. Bulgakov, S. Frank; J. Derrida

In the spotlight - The idea of creation ex nihilo, which is a dogmatic thesis of Christianity. The notion of "creaturely nothingness" is analyzed on the basis of a comparison of metaphysical and postmetaphysical discourses. Metaphysical discourse is represented by the doctrine of Sofia Russian philosophers V1. Soloviev and S. Bulgakov, and a meditation on the nature of the denial of S. L. Frank; post-metaphysical discourse - the concept of differance Jacques Derrida. The goal is to show how the idea of creation ex nihilo provoked new formats of philosophical discourse, and also to trace back the process that occurred in the period of post-metaphysical turn in philosophy: what impact did the critique of classical metaphysics, in particular, the project deconstructivist Jacques Derrida, on ways of thinking about the ideas of creation?

It is shown that the difficulty of the Christian understanding of "creation" as a concept that it is, marking the creation of the world, itself does not belong to this world. Creation is a trait that separates Creator and creation. On the one hand, belongs to the Creator, but not co-eternal to Him. On the other hand, means the beginning of creation, its cause, but does not belong to the creation as its result. In this problem the interface point between the divine and the creaturely there is opinionto as the doctrine of mediation between Creator and creature. Using the model of pan-EN-theism in the definition of its basic concept "positive unity", Solovyov connects the tradition of pantheism in the understanding of God and the dogma of the Holy Trinity. As a result, Absolute as Neoplatonists, received his dual nature: Absolute, not involved in the world and Absolute, involved in the world. Soloviev defined the second as "first matter", "soul of the world", Sophia - Wisdom of God, which will be the intermediary between the Creator and creation. In this case, it is the perfect essence of creation already contains in Sofia as a certain ideal base of God. Revealed that inappropriate attitude to Solovyov's notion of "denial" has led to charges of pantheism.

It was also revealed that, despite the efforts of Bulgakov through the idea of creation to give sophiology maximum Christian character, he ultimately dissolves the concept of creation in the divine essence. The solution is found in thinking Frank about antinomical the coincidence of the Creator and the creation. As a result, the reinterpretation of the nature of the meta-logic of negation as a positive ontological structure.

The result suggested that the heterogeneity created and uncreated aspects of Sofia comes from the impossibility to solve this problem by using the classic metaphysical resource. It is proposed to use post-metaphysical tradition, for example, the understanding of J.Derrida "nothing" as distinguishing beginning.

On the one hand, this understanding nothing is the image and likeness of the infinite divine performance of denial, creating the world and giving him the freedom of conceptualization. On the other hand, it underlines that the creature exists due to the denial of God-His nature.

\section{References}

1. Soloviev, V.S. (1990) Sochineniya v 2 t. [Works in 2 vols]. Vol. 1. Moscow: Mysl'. pp. 581-745.

2. Chanyshev, A.N. (1991) Kurs lektsiy po drevney i srednevekovoy filosofii [Lectures on Ancient and Medieval Philosophy]. Moscow: Vyssh. shk.

3. Losskiy, V1. (1991) Misticheskoe bogoslovie [Mystical Theology]. Kyiv: Put' k istine. pp. 95-261.

4. Kruglova, I.N. \& Kruglov, V.L. (2015) [S.L. Frank and J. Derrida: The need for the impossible]. Fenomenologo-ontologicheskiy zamysel G. G. Shpeta i gumanitarnye proekty XX-XXI vekov [Phenomenological and Ontological Design of G.Shpet and Humanitarian Projects of the 20th - 21st centuries]. Proc. of the International Conference. Tomsk. June 1-7, 2015. Tomsk. pp. 203-214 (In Russian).

5. Losev, A.F. (1983) Vl. Solov'ev [V1. Soloviev]. Moscow: Mysl'.

6. Bulgakov, S.N. (1927) Kupina neopalimaya [The Burning Bush]. Paris: [s.n.].

7. Gurko, E. (2006) Bozhestvennaya onomatologiya: Imenovanie Boga v imyaslavii, simvolizme $i$ dekonstruktsii [Divine Onomatology: The Name of God in Imiaslaviye, Symbolism and Deconstruction]. Minsk: Ekonomopress.

8. Bulgakov, S.N. (1994) Svet Nevecherniy: Sozertsaniya i umozreniya [Unfading Light: Contemplation and Speculation]. Moscow: Respublika. 
9. Abushenko, V.L. (2001) Frank, S.L. In: Gritsanov, A.A. (ed.) Noveyshiy filosofskiy slovar' [The Newest Philosophical Dictionary]. 2nd ed. Minsk: Interpresservis; Knizhnyy dom. pp. 1110-1112.

10. Soloviev, V.S. (1990) Sochineniya v 2 t. [Works in 2 vols]. 2nd ed. Moscow: Mysl'. pp. $548-556$.

11. Frank, S.L. (2000) Sochineniya [Works]. Minsk: Kharvest; Moscow: AST.

12. Novikova, L.I. \& Sizemskaya, I.N. (1997) Russkaya filosofiya istorii [Russian Philosophy Of History]. Moscow: Magistr.

13. Derrida, J. (1999) Differanse. In: Gurko, E. Teksty dekonstruktsii [Texts of Deconstruction]. Tomsk: Vodoley. pp. 124-158.

14. Gurko, E. (1999) Teksty dekonstruktsii [Texts of Deconstruction]. Tomsk: Vodoley.

15. Derrida, J. (2001) Kak izbezhat' razgovora: denegatsii [How to avoid conversation: money payments]. In: Gurko, E. Dekonstruktsiya: teksty i interpretatsiya [Deconstruction: Texts and Interpretation]. Minsk: Ekonompress. 